\title{
Electrochemical and Photocatalytic Properties of Green Nickel Oxide Nanomaterial Synthesized using Plectranthus Amboinicus Plant Leaf Extract
}

\author{
N.B. Arun Kumar', J. Sirajudeen', H.P. Nagaswarupa ${ }^{2}$, C.R. Ravikumar ${ }^{3, *}$, M.R. Anil Kumar', \\ H.C. Ananda Murthy ${ }^{4}, * ;$ \\ ${ }^{1}$ Department of Chemistry, Jamal Mohamed College, Tiruchirappalli 620020, Tamilnadu, India \\ 2PG Centre, Department of Chemistry, Davanagere University, Davanagere 577001, Karnataka, India \\ ${ }^{3}$ Research Centre, Department of Chemistry, East West Institute of Technology, Bangalore 560091, India \\ ${ }^{4}$ Department of Applied Chemistry, School of Applied Natural Science, Adama Science and Technology University, \\ P.O. Box 1888, Adama, Ethiopia \\ *Corresponding authors: E-mail: ravicr128@gmail.com; Tel.: (+91) 9902284932 (C.R. Ravikumar) \\ E-mail: anandkps350@gmail.com; Tel.: (+251) 988683640 (H.C. Ananda Murthy)
}

DOI: $10.5185 /$ amlett.2020.091559

We report the successful synthesis of $\mathrm{NiO}$ nanomaterial by combustion method using Plectranthus amboinicus plant leaves extract. The diffraction pattern and image analysis confirmed the FCC lattice structure for green NiO nanomaterial (g-NONM) with spongy, agglomerated and porous nature. The average energy band gap of g-NONM was found to be $4.10 \mathrm{eV}$. The electrode made of g-NONM exhibited excellent stability in addition to its good reversibility. The g-NONM showed superior photo-decolarisation results for AO dye solution with $33.95 \%$ dye decolorization at $405 \mathrm{~nm}$. The obtained rate constant $k$ value of g-NONM for AO dye is $0.002933 \mathrm{~min}^{-1}$. The prepared g-NONM electrode showed a minimum charge-transfer resistance which is possibly due to its high conductivity as supported by electrochemical impedance studies. The NiO electrode also exhibited very high alcohol sensing ability in alkaline medium as revealed during CV measurement. The best part of the study was the fast reply $(3 \mathrm{~s})$ of the prepared electrode in sensing the drugs at $1 \mathrm{mM}$ concentration solution. In addition, g-NONM can be easily fabricated into stable electrode material for supercapacitors applications. The results suggested that g-NONM can be an efficient and cheaper material for photocatalytic, sensor and supercapacitor applications.

\section{Introduction}

The most considerable, pioneering and rapid growing discipline in the field of science and engineering is nanotechnology with its interdisciplinary knowledge dependence on various scientific disciplines such as physics, chemistry, biology, material science etc. The progress in the field of nanoworld can happen only with the mutual cooperation from experts from many specialized areas of research. Synthesis and application of nanomaterials in various sectors such as catalysis, photocatalysis, photovoltaics, electrocatalytic and biomedical fields has played significant role in the recent advancement of nanoscience and Technology. Nanomaterials have very high surface to volume ratio due to their small size. They can be classified based on their shapes such as nanowire, nanorods, nanotube and nanoflowers etc. [1].

Applications of metal oxide nanomaterials can be found in many industries which produce food, cosmetics, drug, biomaterial and so on [2]. The reason for diverse applications of nanomaterials are due to their extraordinary properties. The properties of metallic oxide nanomaterials (MONMs) such as size, shape, surface effect, electrical and magnetic properties $[3,4]$ differ significantly from those of their bulk materials and polysaccharide templated silica, titania and zirconia nanocomposites [5-7].

Among many versatile MONMs, NiO NM (NONM) with multifunctional and tuneable properties found very attractive to scientific community. $\mathrm{NiO}$ has a band gap energy from 3.2-4.0 eV with high chemical stability. NONM has been diversely applied because of its attractive optical and electrical traits $[\mathbf{8 , 9}]$. NONM was found to have wide range of applications in many areas including electrochemical and catalytic applications $[\mathbf{1 0 - 1 2}]$ in addition to their biomedical applications due to antiinflammatory property $[\mathbf{1 3}]$.

Most of the physicochemical methods of synthesis of NMs have number of harmful effects which restrict their broad range of applications. The preparation of NMs by chemical methods results in the development of various poisonous components on the exterior of NMs [14]. Therefore, application of plant extracts to synthesize NMs would be very viable, effective and beneficial. Bioactive compounds of plants play the role of the reducing agents as well as capping agents to yield more stable, efficient and biocompatible nanostructures [15-18]. The plant identified for this study is Plectranthus amboinicus. It is a semisucculent perennial plant in the family Lamiaceae. 


\section{Advanced Materials Letters www.vbripress.com/aml}

Common names of the plant in English include Indian borage, country borage, Cuban oregano, French thyme, Indian mint, Mexican mint, soup mint and Spanish thyme. Plectranthus amboinicus is thought to have medicinal properties. The aroma of the leaves can be described as a pungent combination of the aromas of oregano, thyme, and turpentine. The leaves are strongly flavoured and used for stuffings of meat and poultry, beef, lamb and game.

The present work was aimed to explore the green combustion synthesis of $\mathrm{NiO} \mathrm{NM}$ using Plectranthus amboinicus plant leaves extract. The as-synthesised green $\mathrm{NiO}$ NM (g-NONM) was characterized by using PXRD, FT-IR, UV-DRS, TGA-DTA and SEM techniques to evaluate its structural, chemical bonding, band gap energy, thermal stability and morphological features. Electrochemical techniques were also employed to evaluate electrode stability and supercapacitance of g-NONMs. CV and EIS techniques were employed to explore the photocatalytic, sensor and supercapacitor applications of g-NONM.

\section{Experimental}

\section{Preparation of plant extract}

The fresh leaves of Plectranthus amboinicus plant were collected from the rural district of Bangalore, India. The collected leaves were washed with deionized water and shade dried for a period of 10 days. $100 \mathrm{~g}$ of the dried leaves were mixed with $250 \mathrm{~mL}$ of water in a $500 \mathrm{~mL}$ beaker and heated to $80^{\circ} \mathrm{C}$ for 10 minutes with constant stirring and later cooled to room temperature. The prepared plant extract was filtered using Whatman filter paper No 1 . The obtained plant extract was stored at $4^{\circ} \mathrm{C}$ for further use.

\section{Synthesis of NiO NMs by green combustion method}

The green $\mathrm{NiO} \mathrm{NM}$ (g-NONM) was synthesised via bio-mediated solution combustion method using Plectranthus amboinicus plant leaves extract as a fuel. The mixture of 1 gram of $\left[\mathrm{Ni}\left(\mathrm{NO}_{3}\right)_{2} \cdot 6 \mathrm{H}_{2} \mathrm{O}\right]$ and $0.5 \mathrm{~mL}$ of Plectranthus amboinicus plant leaves extract was positioned in a muffle furnace maintained at $320 \pm 10^{\circ} \mathrm{C}$. After boiling, a transparent gel was formed and later white foam formed expanded to fill the vessel. Thereafter, combustion of the mixture proceeded rapidly, leaving a white coloured product with an extremely porous structure. The complete combustion process occurred in less than 5 min.

\section{Preparation of carbon paste electrode for sensor study}

A mixture of NONM, graphite powder and silicon oil (ratio 15:70:15) was ground and allowed to settle for about $30 \mathrm{~min}$ in agate mortar. The obtained carbon paste was then filled into a Teflon cavity tube fabricated by our group. The exterior of the filled carbon paste was then smoothened by pressing gently on a weighing paper [19].
$75 \% \mathrm{NiO}+15 \%$ graphite $+10 \%$ PTFE

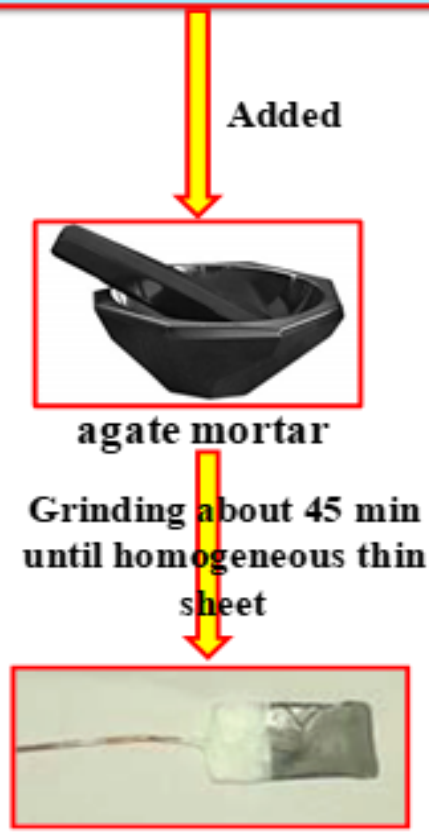

Nickel mesh electrode

Fig. 1. A scheme of preparation of nickel mesh electrode.

\section{Preparation of nickel mesh electrode for galvanostatic charge-discharge study}

A mixture of $75 \%$ as synthesized $\mathrm{NiO}, 15 \%$ graphite and $10 \%$ PTFE solution was taken in an agate mortar and ground for about $45 \mathrm{~min}$, to get a paste.

In order to build up an electrical contact with the nickel mesh and material, the electrode was squeezed at $20 \mathrm{MPa}$ after being covered with paste. A Teflon tape was applied for successful protection of the anode and wire to acquire a terminal with definite dimension of $2 \times 1 \mathrm{~cm}^{2}$ in area (Fig. 1). Prior to its utilization, it was kept in $6.0 \mathrm{M} \mathrm{KOH}$ solution for around $30 \mathrm{~min}$ to activate and acquire efficient contact with the electrolyte [20].

\section{Results and discussion}

\section{PXRD analysis}

X-ray diffraction pattern of prepared g-NONM was recorded using a $\mathrm{Cu}-\mathrm{K} \alpha(\lambda=1.5418 \AA)$ radiation at a scan rate of $2^{\circ} \mathrm{min}^{-1}$. The scans were recorded in the $2 \theta$ (diffraction angle) range from $10-80^{\circ}[\mathbf{2 1 , 2 2}]$. The synthesized material diffraction peaks in PXRD pattern were well corresponding to face centred cubic (fcc) crystal structure. Three characteristic peaks of NONM correspond to planes with Miller indices (111), (202), and (222), as shown in Fig. 2. The average crystallite size of the nanoparticles was calculated by using Scherrer's formula.

$$
\mathrm{D}=\mathrm{K} \lambda / \beta \cos \theta
$$

where $\mathrm{D}$ is a grain size, $\mathrm{K}$ is an empirical constant to 0.9 and $\lambda$ is the wavelength of the CU. K $\alpha$ radiation. B is the full width half maximum value and $\theta$ is the angular 


\section{Advanced}

component of the peak position. The average crystallite size of NONM was found to be $41.8 \mathrm{~nm}$, as calculated from (111) plane $[\mathbf{2 3 , 2 4 ] .}$

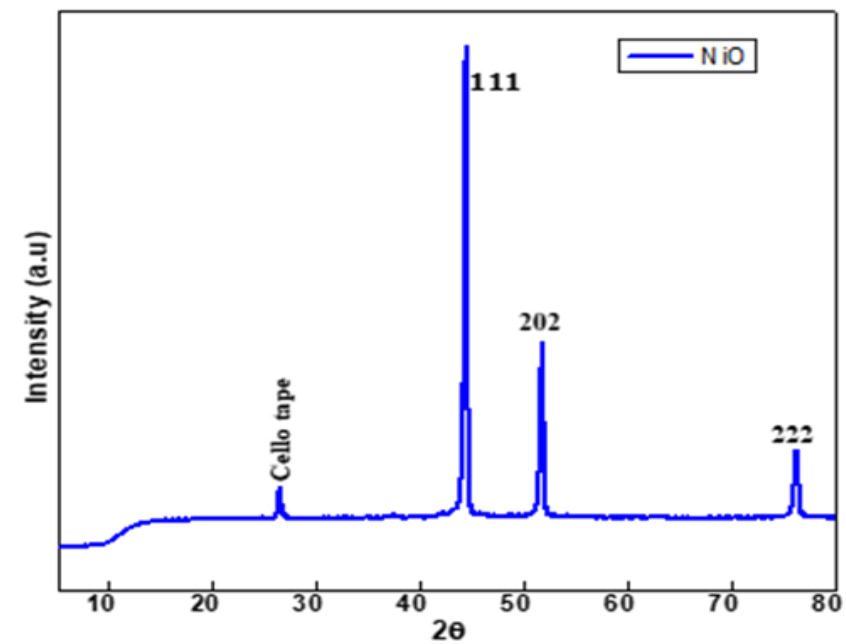

Fig. 2. The PXRD Pattern of g-NONM prepared by Plectranthus amboinicus plant leaves extract.

\section{FTIR studies}

The FTIR spectrum of g-NONM (Fig. 3) exhibited the absorption bands in the range between 4000 and $500 \mathrm{~cm}^{-1}$. The strong band near $3642.7 \mathrm{~cm}^{-1}$ corresponds to $\mathrm{O}-\mathrm{H}$ stretching. The band near $1132 \mathrm{~cm}^{-1}$ is due to $\mathrm{C}-\mathrm{H}$ wagging mode of vibration [25].

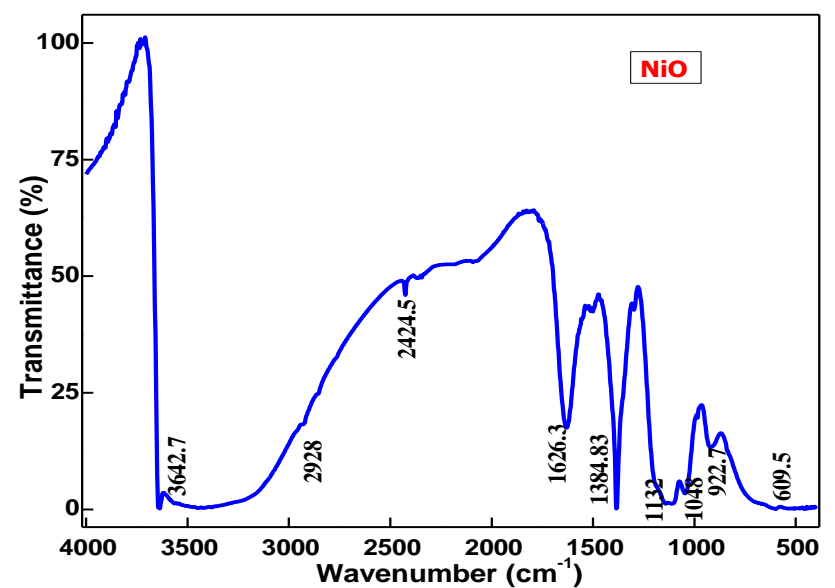

Fig. 3. The FTIR spectrum of g-NONM prepared by Plectranthus amboinicus plant leaves extract.

The $\mathrm{C}=\mathrm{O}$ starching vibration appeared at $1626.3 \mathrm{~cm}^{-1}$. The band at $3642.7 \mathrm{~cm}^{-1}$ corresponds to $-\mathrm{OH}$ stretching of water molecules. The weak band at $2928 \mathrm{~cm}^{-1}$ and $2424.5 \mathrm{~cm}^{-1}$ are assigned to the $\mathrm{C}-\mathrm{H}$ symmetric stretching vibration. The spectrum contains one broad band at $609.5 \mathrm{~cm}^{-1}$ which is characteristic of the stretching vibration hydroxyl group, hydrogen-bonded to $\mathrm{Ni}-\mathrm{O}$. The IR bands at $1048 \mathrm{~cm}^{-1}$ could be attributed to $-\mathrm{C}-\mathrm{O}$ and $-\mathrm{C}-\mathrm{O}-\mathrm{C}$ stretching [26]. All these peaks in the FTIR spectrum confirm the presence of biomolecules at the surface of g-NONM.

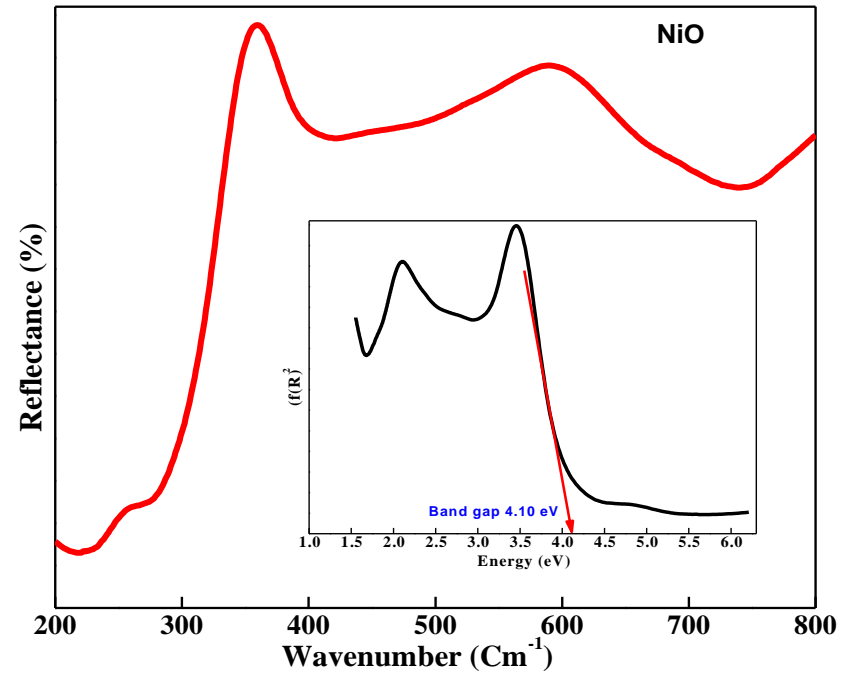

Fig. 4. The UV-DRS reflectance spectra of g-NONM Nanoparticles (inset; Energy Band gap of g-NONM).

\section{UV-DRS studies}

The UV-DRS reflectance spectrum of g-NONM is recorded with a Shimadzu 3600 UV-Visible NIR spectrophotometer and is shown in Fig. 4. The absorption edges are located at $350 \mathrm{~nm}$ for $\mathrm{g}$-NONM which shows that the photo response is in the range of UV light.

Kubelka-Munk equation was used to calculate band gap energy of g-NONM,

$$
\mathrm{F}(\mathrm{R})=(1-\mathrm{R})^{2} / 2 \mathrm{R}
$$

where $R$ is the absolute reflectance of the sample and $F(R)$, the so-called Kubelka-Munk function

Utilizing the reflectance information of the absorption coefficient, the range shows a strong band around $350 \mathrm{~nm}$ which can be ascribed to the g-NONM excitons transition because of surface defects, the peak is ascribed to the transition progress from the valence band to the conduction band in the g-NONM semiconductor.

The $d-d$ transition is forbidden as indicated by Laporte's standards, but due to spin-orbital coupling, it is feebly permitted. The acquired band gap value, $4.2 \mathrm{eV}$ is acceptable and inside the qualities revealed in the writing [27]. Powder samples were stacked into a quartz cell and UV-DRS range was recorded in the scope of 200-800 nm [28].

\section{TGA-DTA analysis}

The TGA-DTA curves containing 3 endothermic peaks for the synthesized g-NONM is depicted in Fig. 5.

The first peak at around $119^{\circ} \mathrm{C}$ corresponds to the loss of adsorbed water molecules, with $2 \%$ weight loss. The second peak observed at $320{ }^{\circ} \mathrm{C}$ is related to the endothermic nature of nickel oxide. The third endothermic peak at around $400{ }^{\circ} \mathrm{C}$ is attributed to the decomposition and intercalated anions with a corresponding weight loss of $8.89 \%$. Weight loss observed in the temperature range between $450^{\circ} \mathrm{C}$ and $650{ }^{\circ} \mathrm{C}$ can be attributed to the loss of intercalated anions. Thus, TGA study showed that $\mathrm{g}$ - 


\section{Advanced Materials Letters www.vbripress.com/aml}

NONM has significant amount of adsorbed-intercalated $\mathrm{H}_{2} \mathrm{O}$ molecules. These $\mathrm{H}_{2} \mathrm{O}$ molecules contribute to the enhanced electrochemical behaviour of electrodes [29-32].

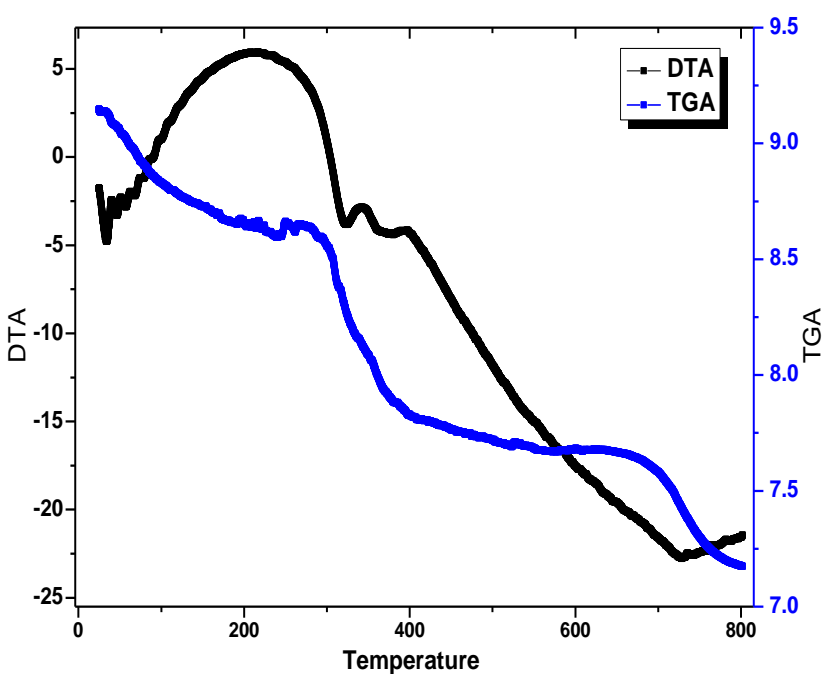

Fig. 5. TGA-DTA curves of g-NONMs.

\section{SEM analysis}

The morphology of the g-NONM was characterized by using SEM [33] technique. SEM image of the g-NONM is shown in Fig. 6.

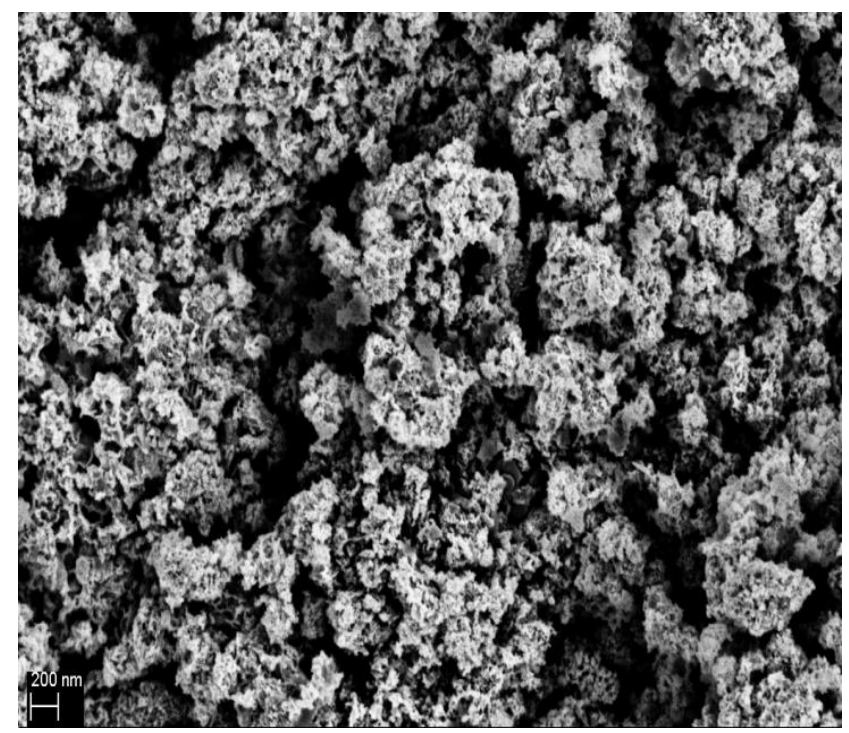

Fig. 6. The SEM micrograph of g-NONM.

The result showed an agglomerated porous shape. The particles are aggregated with irregularly shaped morphology with porous nature having a diameter of $200 \mathrm{~nm}$.

The mechanisms of formation of end product gNONM involves two criteria i.e., reaction system and parameters. The green fuel act as a hydrolysis agent to generate $\mathrm{OH}$ ions along with $\mathrm{Ni}^{2+}$ to form $\mathrm{Ni}(\mathrm{OH})_{2}$ based on reaction systems and parameters, which produce crystal growth $[\mathbf{3 4 , 3 5}]$. The particles of g-NONM were characterized by quite a uniform size with a visible small porosity.

\section{Photo decolorisation of Acid orange (AO) dye}

Photocatalytic investigation of the prepared g-NONM were conducted to survey the decolarisation execution at room temperature for the degradation of Acid Orange (AO) dye. The dye concentration of $20 \mathrm{ppm}$ under UV-light illumination with $60 \mathrm{mg}$ of optimum material dose was used. The photo decolarisation of AO dye for prepared g-NONM is presented in the Fig. 7, with proof of UV-Visible absorption spectra. The g-NONM shows predominant photo-decolarisation results for $\mathrm{AO}$ dye solution which were stretched around $33.95 \%$ dye decolorization appeared in Fig. 7 at $405 \mathrm{~nm}$.

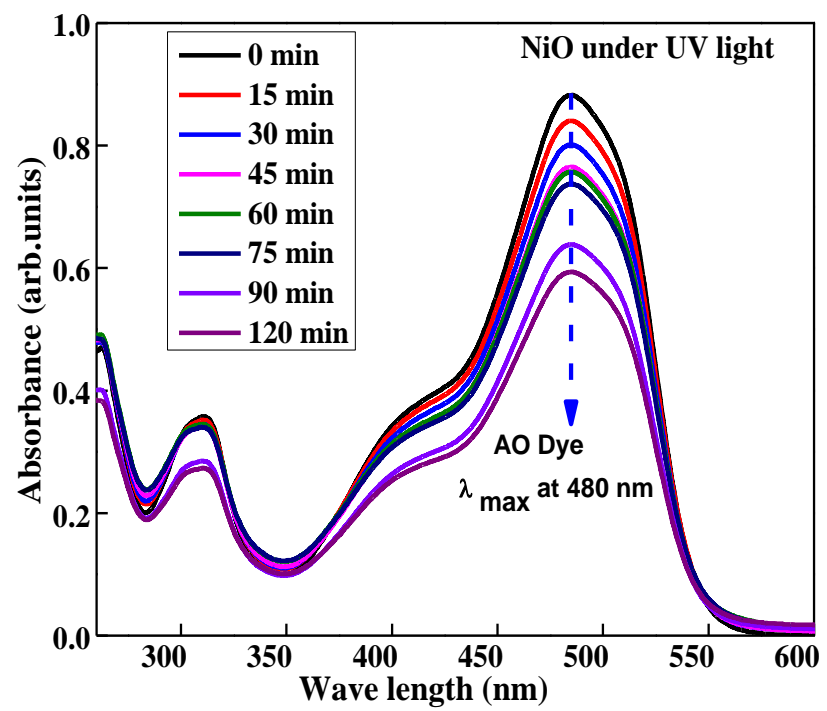

Fig. 7. Absorbance spectra of Acid Orange (AO) for g-NONM under UV light irradiation.

Rate constant $\mathrm{k}$ values of $\mathrm{g}-\mathrm{NONM}$ for $\mathrm{AO}$ are $0.002933 \mathrm{~min}^{-1}$. Thus we report that $\mathrm{g}$-NONM exhibited enhanced photocatalytic activity for the degradation of $\mathrm{AO}$ dye. The increased photocatalytic activity is believed to be due to efficient separation and migration of photogenerated electron-hole pairs. Appearance of the absorption edge in the visible light range was caused by altered synthetic method and may also be due to exterior morphology of prepared g-NONM [36].

Table 1. Rate constants and Kinetic studies of g-NONM under UV light irradiation for the decolorization of Acid Orange (AO).

\begin{tabular}{cccccc}
\hline \multicolumn{6}{c}{ 20 PPM AO+ 60mg NiO + UV } \\
\hline $\mathbf{t}$ & $\mathbf{c}$ & $\mathbf{c} / \mathbf{c 0}$ & $\mathbf{l o g} \mathbf{c} / \mathbf{c o}$ & $\mathbf{- l o g} \mathbf{c} / \mathbf{c o}$ & \%D \\
\hline 0 & 20 & 1 & 0 & 0 & 0 \\
15 & 18.007 & 0.90035 & -0.04559 & 0.045589 & 9.965 \\
30 & 18.056 & 0.9028 & -0.04441 & 0.044408 & 9.72 \\
45 & 17.444 & 0.8722 & -0.05938 & 0.059384 & 12.78 \\
60 & 16.99 & 0.8495 & -0.07084 & 0.070837 & 15.05 \\
75 & 16.606 & 0.8303 & -0.08076 & 0.080765 & 16.97 \\
90 & 14.28 & 0.714 & -0.1463 & 0.146302 & 28.6 \\
120 & 13.21 & 0.6605 & -0.18013 & 0.180127 & 33.95 \\
& & Rate & 0.002937 & \\
\hline \multicolumn{7}{c}{}
\end{tabular}




\section{Advanced}

\section{Electrochemical impedance analysis}

Fig. 8 shows cyclic voltammograms (CVs) recorded for g-NONM at 5 various scan rates $(10,20,30,40$, and $50 \mathrm{mVs}-1)$ in $6 \mathrm{M} \mathrm{KOH}$ electrolyte. The CVs were recorded as per the procedure followed from our earlier work [37-39]. During the CV scans indicated that the reaction of $\mathrm{Ni}^{+2 /} \mathrm{Ni}^{+3}$ is reversible at the g-NONM electrode.

Nyquist plot and equivalent circuit (inset of Fig. 8(d)) of the g-NONM electrode is given in Fig. 8(d). The chargetransfer resistance Rct is a direct measure of the diameter of the semicircle arc on the real axis [40-43]. The EIS data was obtained from the Nyquist plots.
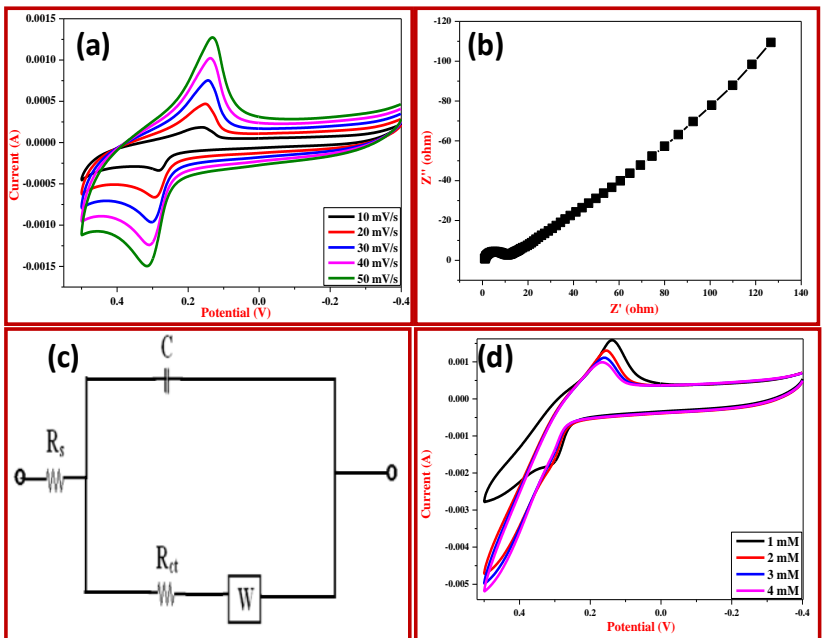

Fig. 8. (a) Cyclic voltammogram of g-NONM (b) AC impedance curve of g-NONM (c) Proposed equivalent circuit of g-NONM (d) Cyclic voltammogram of g-NONM detection of alcohol concentration range 1-4 $\mathrm{mM}$.

The galvanostatic charge-discharge curves (Fig. 9) were recorded for g-NONM at a current density of $5 \mathrm{Ag}-1$ for 1500 cycles. g-NONM electrode exhibited good cycling stability.
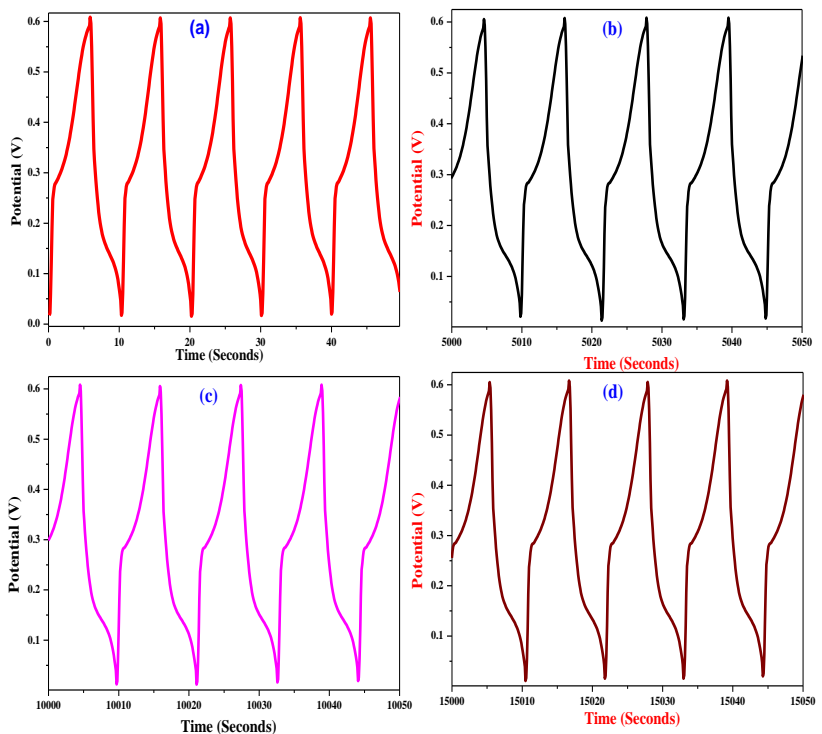

Fig. 9. Galvanostatic Charge-Discharge curve of g-NONM (a) First five cycles (b) 500th Cycles (c) 1000th cycles and (d) 1500th cycles.

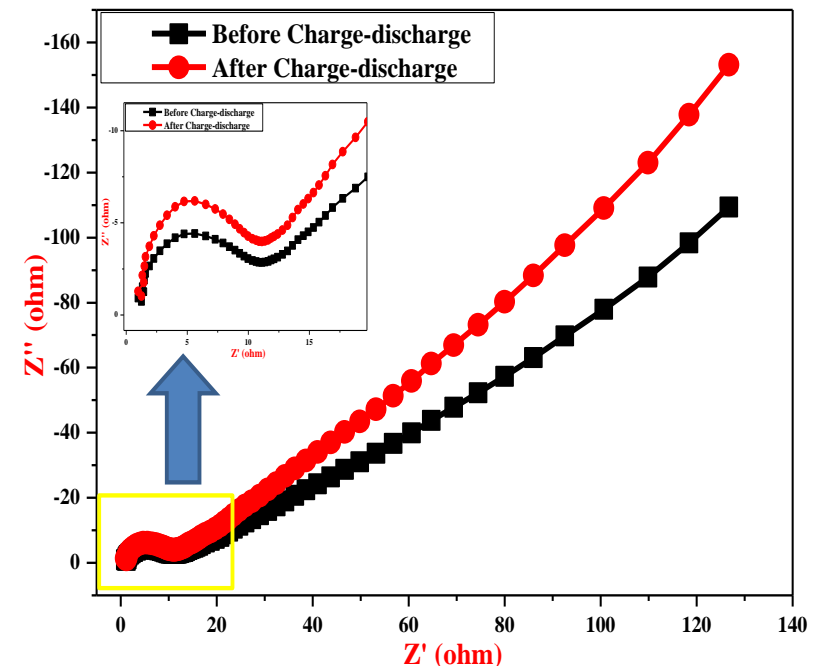

Fig. 10. AC impedance curve of g-NONM before and after 1500 chargedischarge cycles.

Fig. 10 reveals the electrochemical impedance spectra of $\mathrm{NiO}$ electrode before and after charge-discharge subjected to 1500 cycles. After 1500 cycles of chargedischarge, no drastic change in resistance of the electrode was observed as confirmed by AC impedance graph [44]. Thus g-NONM electrode is believed to exhibit greater stability even after charge-discharge behavior. The prepared g-NONM electrode showed a minimum chargetransfer resistance which is possibly due to its high conductivity as supported by electrochemical impedance studies. Therefore, g-NONM can act efficiently as better material for photocatalytic, sensor and supercapacitor applications.

\section{Conclusion}

The green $\mathrm{NiO}$ nanomaterial (g-NONM) was productively prepared by an eco-friendly route using Plectranthus amboinicus plant leaves extract as a fuel. The synthesized material diffraction peaks in PXRD pattern confirmed the face entered cubic crystal structure for g-NONM. SEM analysis indicated the porous and agglomerated nature for g-NONM. The energy band gap of g-NONM was found to be $4.10 \mathrm{eV}$. The g-NONM showed superior Photodecolarisation results for AO dye solution with $33.95 \%$ dye decolorization at $405 \mathrm{~nm}$. The prepared $\mathrm{NiO}$ electrode showed a minimum charge-transfer resistance which is possibly due to its high conductivity as supported by electrochemical impedance studies. The high alcohol sensing ability was observed for g-NONM electrode in alkaline medium as revealed by $\mathrm{CV}$ studies. The study concludes that g-NONM can be an alternative, cheaper and better material for photocatalytic, sensor and supercapacitor applications.

\section{Acknowledgements}

Authors KR, MRA, CRR wish to thank VGST, Govt. of Karnataka, India, (No: VGST/CISEE/2014-15/282) and (VGST/K-FIST-L1/2014-15/GRD360) for extending their support to carry out this research work and Adama Science and Technology University, Ethiopia. 


\section{Advanced Materials Letters www.vbripress.com/aml}

\section{Author's contributions}

Arun Kumar, Sirajuddin, Ravikumar: Conceived and designed the experiments; Performed the experiments.

Anil Kumar, Nagaswarupa and Ananda Murthy: Analysed and interpreted the data; Contributed reagents, materials, analysis tools or data; Wrote the paper.

\section{Conflicts of interest}

The authors declare that they have no conflicts of interest.

\section{Keywords}

Green-NiO NMs, plectranthus amboinicus, photocatalyst, sensor, supercapacitor.

\section{Received: 16 May 2020 \\ Revised: 22 July 2020 \\ Accepted: 23 July 2020}

\section{References}

1. Iqbal, J.; Abbasi, B. A.; Mahmood, T.; Hameed, S.; Munir, A.; Kanwal, S.; Appl. Organometal. Chem., 2019, 33, 4950.

2. Iqbal, J.; Abbasi, B. A.; Ahmad, R.; Mahmood, T.; Ali, B.; Khalil, A. T.; Munir, A.; Appl. Microbiol. Biotechnol., 2018, 102, 9449.

3. Murthy, H.C.A.; Abebe, B.; Tegene, D.Z.; Mat. Sci. Res. Ind., 2018, 15,279

4. Murthy, H.C.A.; Tegene, D.Z.; Abebe, B.; Mat. Res. Express, 2020, 7,5 .

5. Singh, S.K.; Rhee, K.Y.; Lee, S.Y.; Park, S.J.; Macromolecul. Res. 2015, 23, 21.

6. Singh, V.; Singh, S.K.; Intern. J. Bio. Macromole. 2011, 48, 451.

7. Singh, S.K.; Murthy, H.C.A.; Singh, V.; Adv. Mat. Lett. 2017, 7, 673.

8. Barir, R.; Benhaoua, B.; Benhamida, S.; J. Nanomater., 2017, 2017, 1.

9. Sta, I.; Jlassi, M.; Kandyla, M.; Int. J. Hydrogen Energy, 2016, 41, 3291.

10. Sone, B. T.; Fuku, X. G.; Maaza, M.; J. Electrochem. Sci., 2016, 11, 8204.

11. Abbasi, B.A.; Iqbal, J.; Mahmood, T.; Ahmad, R.; Kanwal, S.; Afridi, S.; Mat. Res. Exp., 2019, 6, 8.

12. Khalil, A.T.; Ovais, M.; Ullah, I.; Ali, M.; Shinwari, Z. K.; Hassan, D.; Maaza, M.; Nanomed. Biotechnol., 2018, 46, 838.

13. Pandian, C.J.; Palanivel, R.; Dhananasekaran, S.; Chem. Eng., 2015, 23, 1307.

14. Abebe, B.; Murthy, H.C.A; Zereffa, E.: Eticha, Y.; Mater. Res. Express, 2020, 7, 045011.

15. Kuppusamy, P.; Yusoff, M. M.; Maniam, G. P.; Govindan, N.; Saudi Pharm. J., 2016, 24, 473.

16. Lassoued, A.; Lassoued, M. S.; Dkhil, B.; Ammar, S.; Gadri, A.; J. Mater. Sci. Mater. Electron., 2018, 29, 1.

17. 17. Liu, S.S.; Koyama, M.; Toh, S.; Matsumura, S.; Solid State Ionics, 2014, 262, 460.

18. Ma, Y.; Zhang, J.; Wang, Y.; Chen, Q.; Feng, Z.; Sun, T.; J. Adv. Res., 2018, 5, 180 .

19. Makarov, V. V.; Love, A. J.; Sinitsyna, O. V.; Makarova, S. S.; Yaminsky, I. V.; Taliansky, M. E.; Kalinina, N. O.; Acta Nat., 2014, 6, 35 .

20. Pratapkumar, C.; Prashantha, S. C.; Nagabhushana, H., Anilkumar, M. R.; Ravikumar, C. R.; Nagaswarupa, H.P.; Jnaneshwara, D.M.; J. Alloy. Comp., 2017, 728, 1124.

21. Ravikumar, C.R.; Santosh, M.S.; Nagaswarupa, H.P.; Prashantha, S.C.; Yallappa, S.; Anil Kumar, M.R.; Mater. Res. Express., 2017, 4, 065503 .

22. Thangamani, G.; Deshmukh, K.; Basheer Ahamed, M.; Chidambaram, K.; Saranya, K.C.; Khadeer Pasha, S. K.; J. of Chem. Tech. Res., 2015, 7, 76.

23. Basri, N. H.; Deraman, M.; Suleman, M.; Nor, N. S. M.; Mohamad Dolah, B. N.; Sahri, M. I.; Shamsudin, S.; Int. J. Electrochem. Sci., 2016, 5, 95.

24. Perachiselvi, M.; Samraj, J. J.; Bagavathy, M.S.; Feiona, T.A.; Krishnaveni, P.; Pushpa Laksmi, E.; Swetha, V.; Margreet Leema, M.; John Britto, S.; Annadurai, G.; RJLBPCS, 2018, 3, 4.
25. 25. Chandoul, F.; Moussa, H.; Jouini, K.; Boukhachem, A.; Hosni, F.; Slim, M.; Schneider, F. R.; J. Materials Science: Mat. in Electron., 2019, 30, 348.

26. Thangamani, G.; Deshmukh, K.; Basheer, Ahamed, M.; Chidambaram, K.; Saranya, K. C.; Khadeer Pashal, S. K.; Int. J. Chem.Tech. Res., 2016, 2076, 1

27. Sabouri, Z.; Akbari Hasan, A.; Hosseini, A.; Hashemzadeh, A.; Darroudi, M.; J. Clust. Sci., 2019, 30, 1425.

28. Princess Jeba, D.; Peter, T. A.; Int. J. Res. Advent Technol., 2018, 6, 11.

29. Ullah, M.; Naz, A.; Tariq, Mahmood.; Siddiq, M.; Bano, A.; Int. J. Enhanced Res. Sci. Technol. Engg., 2014, 3, 415.

30. Shruthi, B.; Madhu, B.J.; Bheemaraju, V.; Vynatheya, S.; Veena Devi, B.; Jayashree, G.V.; Ravikumar, C.R.; J. Science: Advanced Materials and Devices, 2017, 2, 93.

31. Lota, K.; Sierczynska, A.; Lotal, G.; Int. J. Electrochem., 2010, 2011, 1

32. Assem, B.; Al-Noaimi, M.; Suleiman, M.; Abdullah S.; Aldwayyan, B. H.; Hadda, T. B.; Salim, F. H.; Ahmed, B.; Ismail, W; Int. J. Mol. Sci., 2013, 14, 23941.

33. El-Kemaryn, M.; Nagy, N.; El-Mehasseb, I.; Mat. Sci. Semicond. Proc. 2013, 16, 1747.

34. Ravikumar, C. R.; Kotteeswaran, P.; Santosh, M.S.; Shruthi, B.; Bheemaraju, V.; Shivakumar, M.S.; Nagaswarupa H.P.; Asian J. Chem. 2016, 28, 221.

35. Jisha, P.K.; Ramachandra, N.; Prashantha, S.C.; Ravikumar, C.R.; Nagaswarupa, H.P.; Nagabhushana, H.; Jnaneshwara, D.M.; Materials Today: Proceedings, 2017, 4, 11706.

36. Abebe, B.; Murthy, H. C. A.; Zereffa, E.; Arabian J. Sci. Engg., 2020, 1 .

37. Anil Kumar, M.R.; Nagaswarupa, H.P.; Ravikumar, C.R.; Prashantha, S.C.; Nagabhushana, H.; Aarti Bhatt, S.; J. Phys. Chem. Solids, 2019, 127, 127.

38. Ravikumar, C. R.; Anil Kumar, M. R.; Nagaswarupa, H. P.; Prashantha, S. C.; Bhatt, A. S.; Santosh, M. S.; Kuznetsov, D.; J. Alloys. Compd., 2018, 738, 332.

39. Inamdar, A. I.; Kim, Y. S.; Pawar, S. M.; Kim, J. H.; Im, H.; Kim, H.; J. Power Sources, 2011, 196, 2393.

40. Ravikumar, C.R.; Kotteeswaran, P.; Bheemaraju, V.; Murugan, A.; Santosh, M.S.; Nagaswarupa, H.P.; Prashantha, S.C.; Anil kumar, M.R.; Shivakumar, M.S.; J. Energy Storage, 2017, 9, 12.

41. Rashmi, B.N.; Sujatha, F. H.; Avinash, B.; Ravikumar, C. R.; Nagaswarupa, H.P.; Anil Kumar, M. R.; Gurushantha, K.; Santosh, M.S.; Inorg. Chem. Commun., 2020, 111, 107580.

42. Anil Kumar, C.R.; Ravikumar, Nagaswarupa, H.P.; Purshotam, B.; Bedasa A.G.; Murthy, H.C.A.; Fedlu, K.S.; Samson, T, J. Environ. Chem. Engg., 2019, 7, 103468.

43. Raveesha, H. R.; Sudhakar, M. S.; Pratibha, S.; Ravikumar, C. R.; Nagaswarupa, H.P.; Dhananjaya, N.; Mat. Res. Express, 2019, 6, 11.

44. Anil Kumar, M.R.; Abebe, B.; Nagaswarupa, H.P.; Murthy, H.C.A.; Ravikumar, C.R.; Fedlu, K.S.; Sci. Rep. 2020, 10, 1249.

\section{Authors biography}

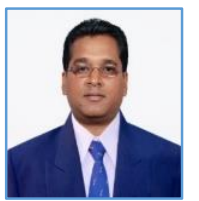

Dr. H. C. Ananda Murthy has been a dedicated faculty member at various prestigious universities in India, Tanzania and Ethiopia for the last 23 years. He is currently working as Associate Professor, Department of Applied Chemistry, Adama Science and Technology University, Adama, Ethiopia, East Africa.

Prof. Ananda has published more than 45 research articles in the journals of international repute and authored 5 books, 3 book chapters \& 6 compendia. He has taught various chemistry courses to UG, PG, and $\mathrm{Ph} . \mathrm{D}$. students of the universities. His research interest mainly includes synthesis and applications of composite materials and Nano-materials. He is currently associated with research projects related to green synthesis of metal and metal oxide nanoparticles for multifunctional applications.

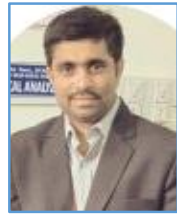

Dr. Ravikumar C.R. is a committed faculty member working as Associate Professor in Chemistry, East West Institute of Technology, Bangalore, India. He has published more than 50 papers in journal of high reputation and presented many papers in conferences. His research interset include electrochemistry, batteries and photocatalysis. He has involved in many research projects and supervisor for $\mathrm{PhD}$ students. 